\title{
Development of cellulose acetate based antimicrobial food packaging materials for controlled release of lysozyme
}

\author{
Seyhun Gemili ${ }^{a}$, Ahmet Yemenicioğlu ${ }^{b}$, Sacide Alsoy Altınkaya ${ }^{a, *}$ \\ a Department of Chemical Engineering, Faculty of Engineering, Izmir Institute of Technology 35430, Gülbahçe Köyü, Urla, Izmir, Turkey \\ ${ }^{\mathrm{b}}$ Department of Food Engineering, Faculty of Engineering, Izmir Institute of Technology 35430, Gülbahçe Köyü, Urla, Izmir, Turkey
}

\section{A R T I C L E I N F O}

\section{Article history:}

Received 20 March 2008

Received in revised form 10 July 2008

Accepted 11 July 2008

Available online 26 July 2008

\section{Keywords:}

Antimicrobial food packaging

Lysozyme

Controlled release

Cellulose acetate

Release kinetics

\begin{abstract}
A B S T R A C T
Antimicrobial packaging materials were obtained by incorporation of lysozyme into cellulose acetate (CA) films. In order to achieve controlled release of lysozyme, the structure of the films was changed from highly asymmetric and porous to dense by modulating the composition of the initial casting solution. The highest release rate, soluble lysozyme activity and antimicrobial activity were obtained with the film prepared from 5\% CA solution including 1.5\% lysozyme. Increasing CA content in the casting solution decreased the porosity of the films, hence, reduced the release rate, maximum released lysozyme activities and the antimicrobial activities of the films. In contrast, immobilized lysozyme activities and the tensile strength of the films increased. The incorporation of lysozyme did not cause significant reductions in tensile strength and elongation at break values except in films prepared with $15 \%$ CA. This study showed the good potential of asymmetric CA films to achieve controlled release in antimicrobial packaging.
\end{abstract}

(c) 2008 Elsevier Ltd. All rights reserved.

\section{Introduction}

In recent years, there has been a great interest in antimicrobial food packaging technologies due to increased food-borne microbial outbreaks caused by minimally processed fresh products and refrigerated products (De Roever, 1998; Devlieghere et al., 2004). Traditionally, antimicrobial additives are mixed into initial food formulations to control microbial growth and extend shelf-life; however, this strategy is not always effective since the protective ability of the antimicrobial agent ceases once it is neutralized in reactions and/or interactions in the complex food system. In addition, the antimicrobial compound directly added into the food cannot selectively target the food surface where spoilage reactions occur more intensively. Antimicrobial packaging is an alternative method to overcome these limitations since it enables controlled release of antimicrobial agent at an appropriate rate during storage, hence, maintains its critical concentration necessary for inhibiting the microbial growth (Appendini and Hotchkiss, 2002). Controlled release systems have been mainly developed for pharmaceutical applications (Langer and Peppas, 1981; Leong and Langer, 1988; Brayden, 2003). Different strategies for achieving controlled release of drugs are well established and studies on both preparation and modeling of drug delivery systems have been reported (Langer and Peppas, 1981; Mallapragada and Peppas, 1997; Richard, 1998; Siepmann et al., 1999; Siepmann and Peppas,

\footnotetext{
* Corresponding author. Tel.: +90 232 7506658; fax: +90 (232) 7506645 .

E-mail address: sacidealsoy@iyte.edu.tr (S.A. Altınkaya).
}

2001; Arifin et al., 2006). However, studies on the development of food packaging films with controlled release properties are limited. The concept of controlled release for food packaging applications was first applied by Han and Floros (1998). They suggested to control the release kinetics by using a multilayer structure which included an outer barrier layer, a matrix layer containing the active agent and a control layer. A similar approach was also proposed by Amparo et al. (2006). On the basis of Han and Floros's work, Buonocore et al. (2005) developed two multilayer films which consist of two external control layers and an inner layer containing the active agent. The same research group has also tried to regulate the release kinetics of active compounds by changing the degree of cross-link of the polymer matrix (Buonocore et al., 2003, 2004). LaCoste et al. (2005) have proposed to use smart blending for developing novel controlled release packaging materials.

The objective of this study was to develop asymmetric and porous cellulose acetate (CA) films for internal food packaging applications and to investigate their feasibility in controlling the release rate of antimicrobial agent, lysozyme. Lysozyme is one of the most studied natural biopreservative for antimicrobial packaging applications (Han, 2000; Quintavalla and Vicini, 2002) due to the increasing consumer health concern and growing demand for healthy foods (Labuza and Breene, 1989; Suppakul et al., 2003). It has been immobilized on polyvinylalcohol (PVOH) beads, nylon 6,6 pellets and cellulose triacetate (CTA) films (Appendini and Hotchkiss, 1997) and incorporated into PVOH films (Buonocore et al., 2003, 2004, 2005; Conte et al., 2007). In this study, lysozyme obtained from hen egg white has been directly blended into cellulose 


\begin{tabular}{|c|c|c|}
\hline \multicolumn{3}{|l|}{ Nomenclature } \\
\hline 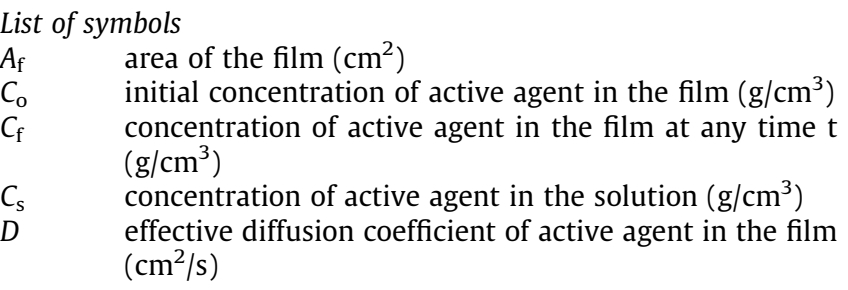 & $\begin{array}{l}K \\
M_{\mathrm{t}} \\
\mathrm{M}_{\infty} \\
t \\
x\end{array}$ & $\begin{array}{l}\text { partition coefficient }\left(\mathrm{cm}^{3} \text { solution } / \mathrm{cm}^{3} \text { film }\right) \\
\text { thickness of the film }(\mathrm{cm}) \\
\text { total amount of active agent desorbed from the film at } \\
\text { any time } t(\mathrm{~g}) \\
\text { total amount of active agent desorbed from the film at } \\
\text { equilibrium }(\mathrm{g}) \\
\text { time }(\mathrm{s}) \\
\text { position in the film }(\mathrm{cm})\end{array}$ \\
\hline
\end{tabular}

acetate solution to prepare films with different morphological characteristics and the release rates from these films have been determined. The relationship among the initial composition of the film forming solution, the resulting morphology and release behavior of the active agent was demonstrated. The antimicrobial activity of the films has also been tested on selected gram-positive and gram-negative bacteria. Recently, different research groups showed the advantage of using asymmetric-membrane capsules and asymmetric coatings on drug tablets to control the release rate of drugs (Herbig et al., 1995; Cardinal et al., 1997; Wang et al., 1998; Thombre et al., 1999a, 1999b, 1999c; Lin and Ho, 2003; Prabakaran et al., 2004; Altinkaya and Yenal, 2006). However, the potential use of asymmetric and porous structures in preparing controlled release food packaging materials has not been investigated. To our knowledge, this is the first study illustrating the development of asymmetric porous films for food packaging applications.

\section{Materials}

Micrococcus lysodeikticus (Sigma M3770) and dialysis tubes (12000 MW, prepared as described in the product manual) were obtained from Sigma Chem. Co. (St. Louis, MO, USA). $\mathrm{Na}_{2}$ EDTA.2$\mathrm{H}_{2} \mathrm{O}$ (ethylenediaminetetraacetate dihydrate) was purchased from Riedel-de Haën (Sigma-Aldrich Laborchemikalien, Seelze, Germany). Fresh hen eggs used in production of lysozyme were obtained from a supermarket in İmir, Turkey. Cellulose acetate with a molecular weight of 50,000 and acetyl content of $39.8 \%$ was obtained from Eastman (Kingsport, TN, USA). Acetone (99\%) was obtained from Merck (Darmstadt, Germany). Escherichia coli (NRRL B-3008) and Bacillus amyloliquefaciens (NRRL NRS-762) were kindly provided by the USDA Microbial Genomics and Bioprocessing Research Unit (Peoria, Illinois).

\section{Methods}

\subsection{Production of lysozyme}

Lysozyme was partially purified by slightly modifying the method of Jiang et al. (2001). Briefly, the egg whites separated carefully without disturbing the egg yolks were first diluted 3-fold with $0.05 \mathrm{M} \mathrm{NaCl}$ solution. The egg white proteins other than the lysozyme were precipitated by adjusting the mixture to $\mathrm{pH} 4$ with $1 \mathrm{~N}$ acetic acid and adding an equal volume of $60 \%$ ethanol $(\mathrm{v} / \mathrm{v})$. After $6 \mathrm{~h}$ at room temperature, the mixture was centrifuged at $15,000 \times \mathrm{g}$ for $15 \mathrm{~min}$ at $4{ }^{\circ} \mathrm{C}$ and the precipitate was discarded. For preparation of lysozyme, the supernatant containing the enzyme was first dialyzed for $21 \mathrm{~h}$ at $4{ }^{\circ} \mathrm{C}$ against three changes of $2 \mathrm{~L}$ distilled water and then lyophilized by using a freeze drier (Labconco, FreeZone, 6 1, Kansas City, MO, USA) (Mecitoğlu et al., 2006). The lyophilized enzyme was stored at $-18{ }^{\circ} \mathrm{C}$ and its activity was determined as $\mathrm{U} / \mathrm{mg}$ before each film preparation.

\subsection{Preparation of films}

Cellulose acetate (CA) dissolved in acetone, and lysozyme and/ or $\mathrm{Na}_{2}$ EDTA dissolved in distilled water were mixed under continuous magnetic stirring for $30 \mathrm{~min}$. at $920 \mathrm{rpm}$ in a tightly closed and sealed bottle to prevent evaporation. The weight percentages of acetone, lysozyme and $\mathrm{Na}_{2}$ EDTA in the solutions were kept constant at $80 \%, 1.5 \%$ and $1.2 \%(\mathrm{w} / \mathrm{w})$, while CA and water concentrations were changed between $5 \%$ and $15 \%(\mathrm{w} / \mathrm{w})$ and 2.3 and $13.8 \%$ $(\mathrm{w} / \mathrm{w})$, respectively. The mixed solution was cast on a polypropylene substrate with the aid of an automatic film applicator (Sheen, Automatic film applicator-1133 N, Kingston, England) at a speed of $100 \mathrm{~mm} / \mathrm{s}$. The thickness of the film was adjusted by a four-sided applicator with a gap size of 300 microns. The cast film was immediately placed in an environmental chamber (Siemens, Simatic OP7, Massa Martana, Italy) and dried for $30 \mathrm{~min}$ at $25^{\circ} \mathrm{C}$ and $40 \%$ relative humidity.

\subsection{Release tests}

The release tests were conducted for both dense and porous sides of the films separately by using a hand made glass apparatus shown in Fig. 1. In this apparatus, film samples ( $5 \mathrm{~cm}$ in diameter) were squeezed between two glass plates one of which contained a circular hole with a diameter of $4 \mathrm{~cm}$ at the center. To prevent contact of water with the protected side of the film, two silicon o-rings (full diameter: $6 \mathrm{~cm}$, inside diameter: $4 \mathrm{~cm}$ ) were placed on both sides of the films. The apparatus was fixed with two rubber attachments from both sides and placed into a glass Petri dish $(10 \mathrm{~cm}$ in diameter) containing $50 \mathrm{~mL}$ distilled water at $4{ }^{\circ} \mathrm{C}$ and stirred magnetically at $240 \mathrm{rpm}$ with a $2 \mathrm{~cm}$ long Teflon coated rod. The Petri dishes were covered tightly with parafilms and with their glass lids to prevent evaporation during long release periods. The lysozyme activity in the release medium was monitored by taking $0.6 \mathrm{~mL}$

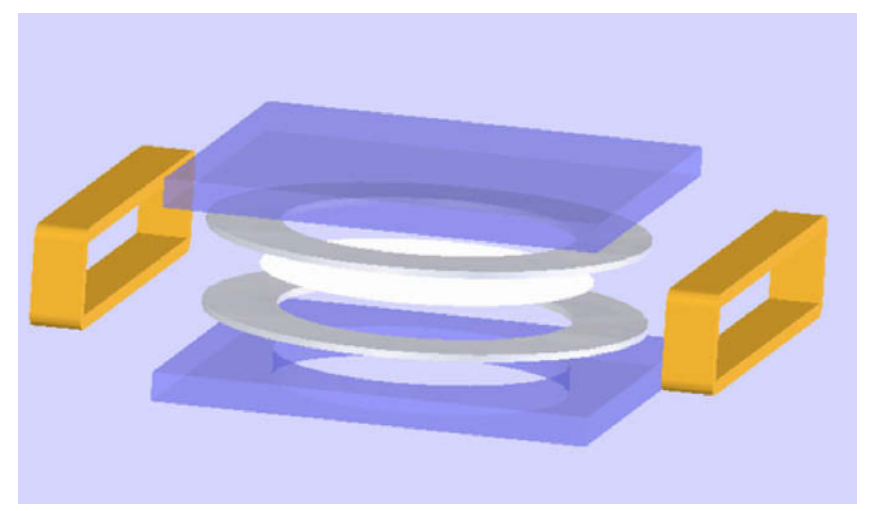

Fig. 1. The experimental set-up used in release tests of porous or dense surfaces of cellulose acetate films. 
samples at different time periods and assaying released soluble activity three times by using the method given in Section 3.4. One millilitre samples were also taken periodically to determine lysozyme release kinetics from increased protein content in the solution. Protein concentration was measured spectrophotometrically by reading absorbance of the samples at $280 \mathrm{~nm}$. The sample used in determination of protein content was rapidly poured back into the release test solution.

\subsection{Determination of soluble lysozyme activity}

The activity of soluble lysozyme was determined as given in Mecitoğlu et al. (2006) by measuring the decrease in absorbance of $M$. lysodeikticus suspension $(0.26 \mathrm{mg} / \mathrm{ml})$ prepared in $0.05 \mathrm{M}$ Na-phosphate buffer at $\mathrm{pH} 7.0$. A volume of $2.3 \mathrm{ml}$ of the substrate was mixed with $0.2 \mathrm{ml}$ of lysozyme solution. The temperature of the reactants was brought to $30^{\circ} \mathrm{C}$ before mixing by incubation for $5 \mathrm{~min}$ at this temperature. The decrease in absorbance was monitored at $660 \mathrm{~nm}$ for $2 \mathrm{~min}$ at $30^{\circ} \mathrm{C}$ by using a UV/VIS spectrophotometer (PerkinElmer, Lambda 45, USA) equipped with a constant temperature cell holder. Activity was calculated from the slope of the initial linear portion of absorbance vs. time curve and expressed as Unit or percent initial activity. One Unit was defined as 0.001 change in absorbance within a 1-min time interval. The analyzes were carried out in triplicate.

\subsection{Determination of the immobilized lysozyme activity retained in the films}

The immobilized lysozyme activity was determined as described by Mecitoğlu et al. (2006). The films used in release studies were cut into 2 pieces, placed into glass Petri dishes and brought into contact with $25 \mathrm{ml} \mathrm{M}$. lysodeikticus suspension $(0.26 \mathrm{mg} / \mathrm{ml})$ at $30^{\circ} \mathrm{C}$ prepared in $0.05 \mathrm{M}$ Na-phosphate buffer at $\mathrm{pH}$ 7.0. The petri dishes were kept in an incubator at $30^{\circ} \mathrm{C}$ and the decrease in absorbance at $660 \mathrm{~nm}$ was monitored periodically. The lysozyme activity of the films were determined from the slopes of the initial linear portions of absorbance vs. time curves and these values were converted to Unit and divided by the area of the films to obtain activity per $\mathrm{cm}^{2}$ of the film $\left(\mathrm{U} / \mathrm{cm}^{2}\right)$. The average of two activity measurements was used in all calculations.

\subsection{Determination of protein content}

Protein content was determined according to Lowry method by using bovine serum albumin as a standard (Harris, 1987). The average of five measurements was used to determine the protein content.

\subsection{Test of antimicrobial activity of the films}

The antimicrobial activity of (1) control films and (2) lysozyme, (3) $\mathrm{Na}_{2}$ EDTA or (4) lysozyme and $\mathrm{Na}_{2}$ EDTA containing films was determined with the zone inhibition assay by using $E$. coli (NRRL B-3008) and B. amyloliquefaciens (NRRL-NRS 762) as test microorganisms (Güçbilmez et al., 2007). E. coli and B. amyloliquefaciens were grown overnight in nutrient broth at 37 and $30^{\circ} \mathrm{C}$, respectively. For antimicrobial tests, 24 discs $(1.3 \mathrm{~cm}$ in diameter) were excised from each film with a cork borer under aseptic conditions. Half of these discs were tested for antimicrobial activity of their porous sides, the other half for antimicrobial activity of their dense sides. The $\mathrm{Na}_{2}$ EDTA containing films were used only for $E$. coli to make it susceptible to lysozyme action. The discs were placed onto PCA plates seeded with $7.1 \times 10^{8} \mathrm{CFU} / \mathrm{mL}$ and $1.4 \times 10^{7} \mathrm{CFU} / \mathrm{mL}$ of E. coli or B. amyloliquefaciens, respectively. Petri plates were incubated for 2 days (at $37^{\circ} \mathrm{C}$ for E. coli or at $30^{\circ} \mathrm{C}$ for B. amyloliquefac- iens) and the diameter of the clear and fully formed zones (ffz) were measured with a digital compass. The total area of ffz (as $\mathrm{cm}^{2}$ ) was used to evaluate the antimicrobial potential of a film. The number of partially formed zones (pfz) and no formed zones (nfz) were reported separately. The pfz refers to clear crescent shaped areas formed at one side of the discs and indicates the heterogeneity of antimicrobial activity of the films.

\subsection{Mechanical properties of the films}

The tensile strength of the films was measured with a Testometric M500-100 kN (Lancashire, England) testing machine. The film samples were strained at a constant rate of $0.25 \mathrm{~mm} / \mathrm{min}$ until failure. The test method and sample preparation were in accordance with the ASTM D 882-02 standard. Samples $5 \mathrm{~mm}$ in width and $50 \mathrm{~mm}$ in gauge length were used for the tests. At least, five specimens of each type of the films were used for the tests and tensile properties were calculated from the plot of stress versus strain.

\subsection{Morphological characterization of the films}

Morphology of the films was examined by scanning electron microscopy (SEM). (Philips XL-30 S FEG, FEI Company, Eindhoven, Netherlands). Samples were coated with gold palladium using a Magnetron Sputter Coating Instrument.

\subsection{Determination of diffusion coefficient of lysozyme}

The diffusion coefficient of lysozyme in the films was determined by combining the release kinetics measurements with the mathematical model presented below. During a typical release experiment, a polymer film with a thickness of $\mathrm{L}$ is placed in a well stirred limited volume of solution. If it is assumed that there is no chemical reaction between the active compound and the film, mass transfer in the film takes place only by diffusion and diffusion coefficient of active compound in the film, D, is constant, then Fick's second law is used to describe the change in the concentration of active compound in the film with respect to time and position:

$\frac{\partial C_{\mathrm{f}}}{\partial t}=D \frac{\partial^{2} C_{\mathrm{f}}}{\partial x^{2}}$

The solution of Eq. (1) requires one initial and two boundary conditions. One side of the films was made impermeable for the desorption of active compound into the solution, Thus:

$x=0 \quad \frac{\partial C_{\mathrm{f}}}{\partial x}=0$

The rate at which active compound leaves the film from the water contacting surface is always equal to that at which it enters the solution. This condition is

$x=L \quad V_{\text {sol }} \frac{\partial C_{\mathrm{s}}}{\partial t}=-D A_{\mathrm{f}} \frac{\partial C_{\mathrm{f}}}{\partial x}$

Eq. (3) indicates the fact that the concentration of active compound in the solution depends only on time since the solution is well stirred, thus, sum of its amounts in solution and in the film remains constant as diffusion proceeds. If the concentration within the surface of the film is related to that in the solution through a partition coefficient, $K$,

$x=L \quad C_{\mathrm{f}}=K C_{\mathrm{s}}$

then, Eq. (3) is rewritten as follows:

$x=L \quad a \frac{\partial C_{\mathrm{f}}}{\partial t}=-D \frac{\partial C_{\mathrm{f}}}{\partial x}$

where $a$ is given by 
$a=\frac{V_{\text {sol }}}{K A_{\mathrm{f}}}$

Initially, the antimicrobial agent is entrapped into the polymer film at a uniform concentration of $C_{0}$. Then, the initial condition is $t=0 \quad C_{\mathrm{f}}=C_{0}$

A solution of these model equations from Eq. (1) through Eq. (7) is presented in a classical book of Crank (1975). In a form expressing the ratio of total amount of active compound desorbed from the film at any time $t, \mathrm{M}_{t}$, to the amount desorbed at equilibrium, $\mathrm{M}_{\infty}$, the solution is

$\frac{M_{t}}{M_{\infty}}=1-\sum_{n=1}^{\infty} \frac{2 \alpha(1+\alpha)}{1+\alpha+\alpha^{2} q_{\mathrm{n}}^{2}} \exp \left(-D q_{\mathrm{n}}^{2} t / L^{2}\right)$

where $\alpha=\frac{a}{K L}$ and the $q_{n}$ s are the non-zero positive roots of Eq. (9) which were determined by plotting $\mathrm{f}\left(q_{n}\right)=\tan q_{n}+\alpha q_{n}$ as a function of $q_{n}$ and then observing the points where $\mathrm{f}\left(q_{n}\right)$ becomes zero.

$\tan q_{\mathrm{n}}=-\alpha q_{\mathrm{n}}$

The diffusivity of active compound in the film was determined by minimizing the difference between Eq. (8) and experimental uptake curves using solver tool in excel.

It should be noted that Fick's second law given by Eq. (1) is valid for an isotropic medium in which structure and diffusion properties are the same in all directions. Crank (1975) has shown that Eq. (1) can also be used to determine diffusion rates in anisotropic media if the direction of diffusion is chosen to be that of a principal axis. In our experiments, this condition is satisfied by fixing the films between two glass plates and allowing the contact of just one surface of the films with water by using the apparatus shown in Fig. 1. It should also be pointed out that in our case the diffusion coefficient of active agent that is determined from Eq. (8) corresponds to the effective diffusion coefficient. The effective diffusion coefficient relates the diffusivity of the active ingredient in the fluid to the porosity and tortuosity of the film (Smith and Herbig, 1992).

\section{Results and discussion}

\subsection{The morphology of the films}

The films used in this study were prepared by a dry phase inversion technique. In this technique, the polymer dissolved in a mixture of a volatile solvent (acetone) and a less volatile nonsolvent (water) is cast on a support and exposed to an air stream. During drying of the solution, fast solvent evaporation leads to a decrease in solubility of the polymer, then phase separation into polymer lean and polymer rich phases takes place. The polymer rich phase forms the matrix of the film while the polymer lean phase fills the pores. Consequently, porous structures with different degree of asymmetry are obtained. We tried to control the release rate of the antimicrobial agent by varying the degree of the asymmetry and the porosity of the films. These structural parameters can be optimized by changing phase inversion processing conditions such as evaporation temperature, relative humidity, wet casting thickness as well as the composition of the membrane forming solution. Fig. 2a-c illustrate the influence of the initial casting composition on the structure of the films through SEM pictures. In these images, the double arrow shows the thickness of the films. Upper sides of the films are the dense surfaces of the films, while, bottom sides of the films correspond to the porous surfaces. Characterization data obtained by analysis of SEM images are listed in Table 1. As expected, addition of low concentration of CA (5\%) to the casting solution created a highly porous structure with a very thin dense skin layer at the top surface (Fig. 2a). With increased CA/acetone a

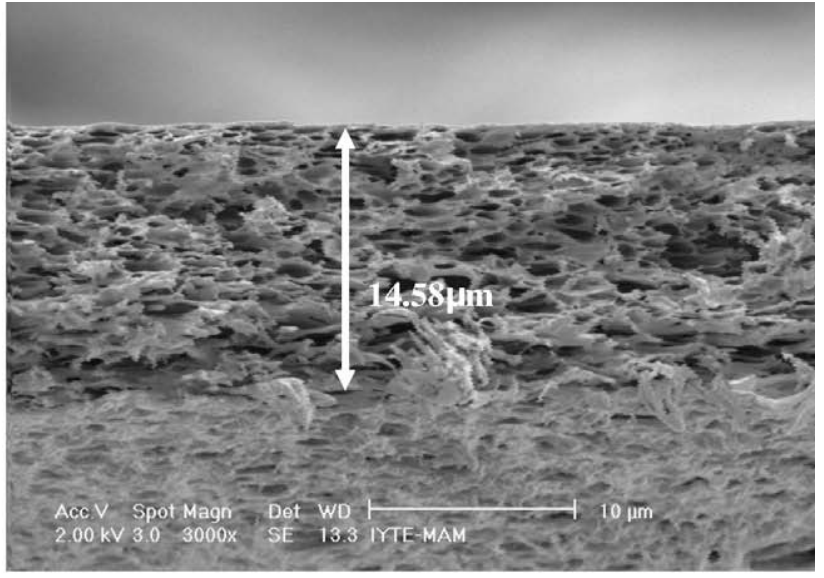

b

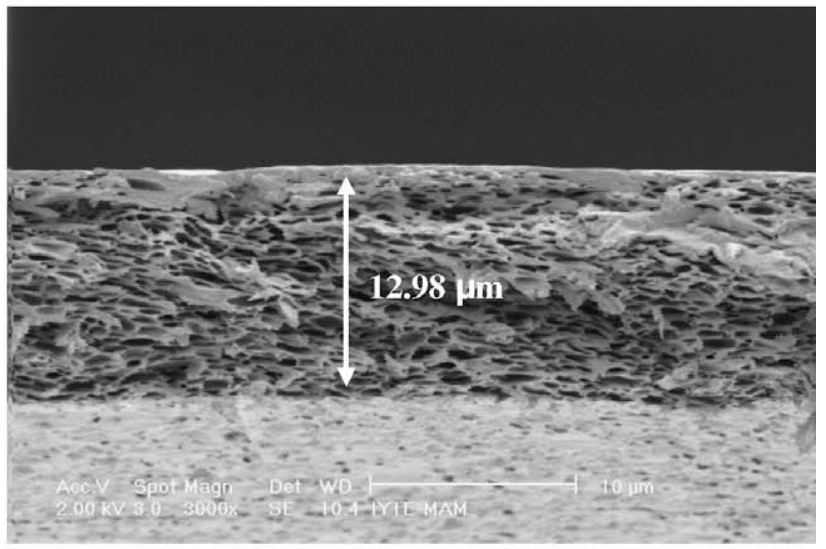

C

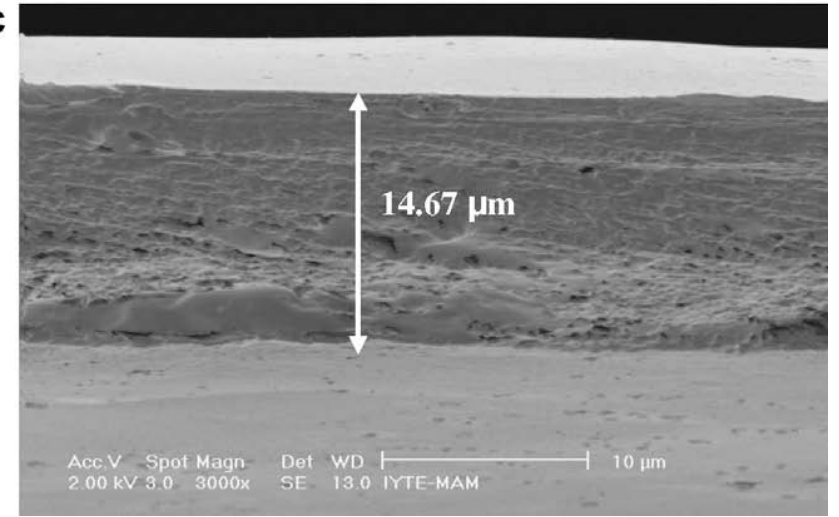

Fig. 2. SEM of the cross-sections of different cellulose acetate films (CA/acetone water/lysozyme weight percentages in film forming solutions were (a) 5/80/13.5 1.5 , (b) $10 / 80 / 8.5 / 1.5$, (c) $15 / 80 / 3.5 / 1.5$; porosity of all films increases from top to bottom; magnification, $3000 \times$ ).

ratio in the casting solution, relatively thicker skin layers and less porous substructures formed and average pore size of the films decreased. Due to presence of macrovoids, the film cast with 5\% CA was found thicker than that prepared with $10 \%$ CA solution.

\subsection{Effect of film composition on released lysozyme activity}

Due to their asymmetric structure, release studies were conducted separately for both dense and porous sides of the films. Antimicrobial packaging is mostly applied to refrigerated foods, thus, the release tests were conducted at $4{ }^{\circ} \mathrm{C}$. As seen in Table 2, the highest amount of activity release occurred from the films prepared with 5\% CA. At the dense and porous surfaces of these films, the maximum activities released reached to 1326 and $1752 \mathrm{U} / \mathrm{cm}^{2}$ 
Table 1

Morphological characterization of lysozyme containing cellulose acetate films

\begin{tabular}{|c|c|c|c|c|c|c|c|}
\hline \multicolumn{4}{|c|}{ Compositions $^{\mathrm{a}}$ (wt\%) } & \multirow[t]{2}{*}{ Total thickness $(\mu \mathrm{m})$} & \multirow[t]{2}{*}{ Skin layer thickness $(\mu \mathrm{m})$} & \multirow[t]{2}{*}{ Pore size $(\mu \mathrm{m})$} & \multirow[t]{2}{*}{ Porosity (\%) } \\
\hline CA & Acetone & $\mathrm{H}_{2} \mathrm{O}$ & Lysozyme & & & & \\
\hline 5 & 80 & 13.5 & 1.5 & 14.58 & - & 0.995 & 30.53 \\
\hline 10 & 80 & 8.5 & 1.5 & 12.98 & 1.27 & 0.716 & 29.06 \\
\hline 15 & 80 & 3.5 & 1.5 & 14.67 & 2.63 & 0.403 & 1.37 \\
\hline
\end{tabular}

a Weight percentages of $\mathrm{CA} /$ acetone/water/lysozyme in film forming solutions.

Table 2

Maximum released and immobilized activities of lysozyme at different surfaces of cellulose acetate films

\begin{tabular}{|c|c|c|c|c|c|c|}
\hline \multirow[t]{2}{*}{ Compositions $^{\mathrm{a}}$} & \multirow[t]{2}{*}{ Film surface } & \multirow[t]{2}{*}{ Max. released activity ${ }^{\mathrm{b}}\left(\mathrm{U} / \mathrm{cm}^{2}\right)$} & \multirow[t]{2}{*}{ Time to reach max. activity (min) } & \multicolumn{2}{|l|}{ Recovery $^{\mathrm{c}}(\%)$} & \multirow[t]{2}{*}{ Immobilized activity $^{\mathrm{d}}\left(\mathrm{U} / \mathrm{cm}^{2}\right)$} \\
\hline & & & & Current value & Corrected value & \\
\hline \multirow[t]{2}{*}{$5 / 13.5$} & Porous & $1752 \pm 0$ & 6 & 76 & 30 & 80 \\
\hline & Dense & $1326 \pm 154$ & 1448 & 57 & 23 & 88 \\
\hline \multirow[t]{2}{*}{$10 / 8.5$} & Porous & $688 \pm 164$ & 36 & 27 & 11 & 180 \\
\hline & Dense & $273 \pm 16$ & 126 & 11 & 4.2 & 185 \\
\hline \multirow[t]{2}{*}{$15 / 3.5$} & Porous & $157 \pm 17$ & 6 & 6.2 & 2.5 & 68 \\
\hline & Dense & $272 \pm 16$ & 246 & 11 & 4.3 & 338 \\
\hline
\end{tabular}

a Weight percentages of CA/water in film forming solutions. Weight percentages of acetone and lysozyme in all film forming solutions were $80 \%$ and $1.5 \%$, respectively.

b The lysozyme used in the film forming solution contained $19,165 \mathrm{U} / \mathrm{mg}$ activity.

c (Maximum released activity/incorporated activity) $\times 100$.

d Immobilized activities left in films following $1700 \mathrm{~min}$ release test in distilled water at $4{ }^{\circ} \mathrm{C}$.

which corresponded to $23 \%$ and $30 \%$ of the total activities incorporated into the films, respectively. Thus, it seems that a significant portion of activity maintained in the films in immobilized form or it was lost during film formation by the effect of acetone. The enzyme activity released from the porous surface decreased sharply at the beginning of the release test (Fig. 3). Part of the lost activity was then recovered, however, the reductions and increases in activity continued until the end of the release test which last almost $30 \mathrm{~h}$ (results in Fig. 3 were given only for the first $1.2 \mathrm{~h}$ ). The initial release rate of enzyme was found slower from the dense surface of films prepared with 5\% CA. In addition, reductions in released enzyme activity from dense surfaces were also less pronounced than those from porous surfaces and as a result enzyme retained $25 \%-40 \%$ more activity between 23 and $33 \mathrm{~h}$ of release test (results were not given). A similar trend was also observed in activity profiles released from the dense and porous sides of films cast with $10 \%$ CA; however, significantly lower lysozyme activity release was detected from these films and the maximum activity released from these porous surfaces reached to $11 \%$ of total activity incorporated into them. These results suggest that the stability of released soluble lysozyme depends on its previous location (dense or porous parts) in the films. This may be due to different changes in conformation of enzyme exposed to different acetone concentrations for various times during the film drying process. On the other hand, a slightly lower amount of lysozyme release occurred from porous surface of the film prepared with 15\% CA compared to the amount released from its dense surface. This can be explained by limited amount of lysozyme present in the thin porous area of these films.

The overall results of release tests clearly demonstrate that the release rate of lysozyme from the films can be tailored by changing the composition of the initial casting solution that changes the

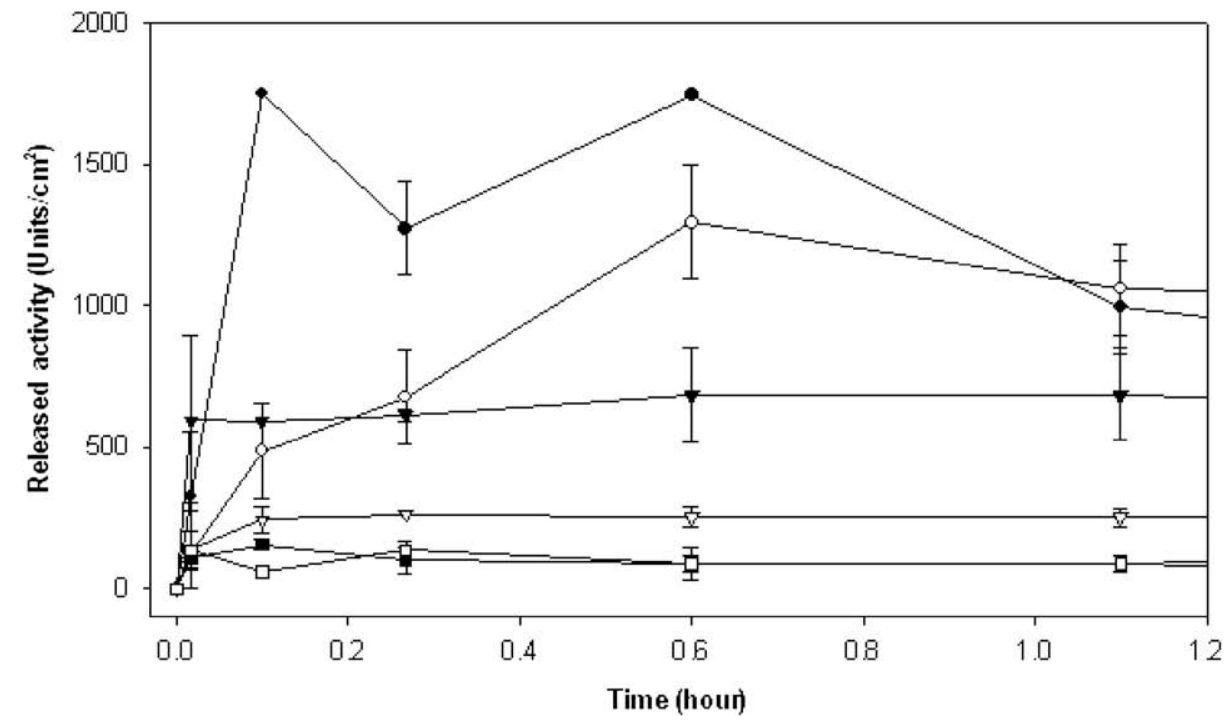

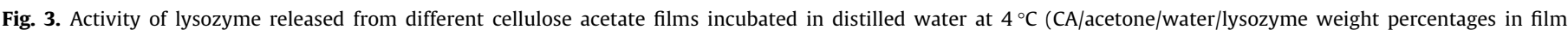

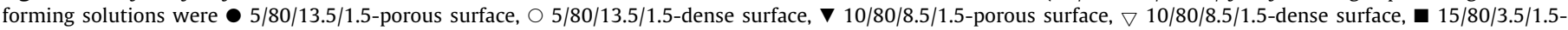
porous surface, $\square$ 15/80/3.5/1.5-dense surface). 
structural properties of the films. Formation of much more dense structure with increased CA content in the film causes a sharp decrease in the release rate due to higher mass transfer resistance in the matrix. It is expected that the influences of pore size and porosity of the matrix are more critical for the release of a large molecule such as lysozyme than that of a smaller size active agent. Phase inversion method used in this study allows easy control over the structural parameters of the films if the dynamics of the phase inversion process is clearly understood. We have quantified the dynamics of the phase inversion process from a mathematical model developed previously in our group (Altinkaya and Ozbas, 2004) and predicted the influence of the initial casting composition on the final structure of the films.

\subsection{Effect of film composition on immobilized lysozyme activity}

The films used in release tests were also assayed for their remaining immobilized enzyme activity. In antimicrobial packaging, it is generally intended to maintain most of the antimicrobial activity in soluble form; however, some immobilized antimicrobial activity may also be beneficial to maintain film sterility during storage of foods. As seen in Table 2, the immobilized activities at dense and porous surfaces of the films prepared with $5 \%$ and $10 \%$ CA solutions were similar. Increasing CA content from $5 \%$ to $10 \%$ in the films caused 2 fold higher immobilized lysozyme activity as the film structure changed from highly porous to dense. It should also be noted that significantly higher immobilized activity was measured at the dense than at the porous side of the film containing $15 \%$ CA. This can be explained by the high amounts of immobilized lysozyme at this surface. It is also possible that at the end of release test lasting for $28 \mathrm{~h}$, equilibrium was not fully achieved between the highly dense surface of this film and surrounding medium. Thus, the late release of some residual lysozyme into $M$. lysodeikticus solution from dense surface of these films could also increase the immobilized activity. These results indicate that immobilized lysozyme activity depends on the structure of the films. The change from porous to dense structures caused an increase in the amount of trapped and immobilized lysozyme in the films.

\subsection{Effect of film composition on antimicrobial activity}

For antimicrobial activity measurements, CA films without lysozyme, with lysozyme and lysozyme combined with $\mathrm{Na}_{2}$ EDTA were used. Lysozyme was mixed with EDTA to make it effective against E. coli which is a gram-negative bacterium. Part of the antimicrobial test results were reported in Table 3 in terms of number of fully formed zones (ffz), partially formed zones (pfz) and number of no formed zones (nfz).

In tests conducted for E. coli, no zone formation was observed around lysozyme and $\mathrm{Na}_{2}$ EDTA free control films as expected. On

\section{Table 3}

Number of fully formed zones (ffz), partially formed zones (pfz) or no formed zone $(\mathrm{nfz})^{\mathrm{b}}$ obtained during antimicrobial tests of different cellulose acetate films against E. coli

\begin{tabular}{lll}
\hline Composition $^{\mathrm{a}}$ & Porous surface & Dense surface \\
\hline $5 / 13.8 / 0 / 1.2$ & $4 \mathrm{ffz} / 1 \mathrm{pfz} / 7 \mathrm{nfz}$ & $12 \mathrm{ffz}$ \\
$5 / 12.3 / 1.5 / 1.2$ & $12 \mathrm{ffz}$ & $10 \mathrm{ffz} / 2 \mathrm{nfz}$ \\
$10 / 8.8 / 0 / 1.2$ & $12 \mathrm{ffz}$ & $2 \mathrm{ffz} / 10 \mathrm{nfz}$ \\
$10 / 7.3 / 1.5 / 1.2$ & $11 \mathrm{ffz} / 1 \mathrm{pfz}$ & $4 \mathrm{ffz} / 2 \mathrm{pfz} / 6 \mathrm{nfz}$ \\
$15 / 3.8 / 0 / 1.2$ & $2 \mathrm{ffz} / 10 \mathrm{nfz}$ & $12 \mathrm{nfz}$ \\
$15 / 2.3 / 1.5 / 1.2$ & $3 \mathrm{ffz} / 9 \mathrm{nfz}$ & $12 \mathrm{nfz}$ \\
\hline
\end{tabular}

a Weight percentages of $\mathrm{CA} /$ water/lysozyme/ $\mathrm{Na}_{2} \mathrm{EDTA}$ in film forming solutions. Weight percentage of acetone was $80 \%$ for all films.

${ }^{b}$ Controls of films lacking lysozyme and/or $\mathrm{Na}_{2}$ EDTA gave $12 \mathrm{nfz}$. the other hand, clear zones surrounding most of the films containing a combination of $\mathrm{Na}_{2}$ EDTA and lysozyme were measured as illustrated in Fig. 4. This result indicated diffusion of antimicrobials from the films and subsequent growth inhibition of E.coli in the medium. Fig. 5a shows that total area of the fully formed zones, hence, the antimicrobial activities of the films containing both lysozyme and $\mathrm{Na}_{2}$ EDTA decreased with increased CA content in the films. In addition, when the dense surfaces instead of porous surfaces were brought into contact with the agar medium, the antimicrobial activities declined by $37 \%, 70 \%$ and $100 \%$ for the films prepared with 5\% CA, 10\% CA and 15\% CA solution, respectively. This is an expected result since the porous surfaces of most of the films gave higher soluble lysozyme activity during release tests. The dense surfaces of the films cast with 15\% CA solution did not show any clear zone formation. In contrast, limited diffusion of antimicrobial agents from the porous surfaces of these films into the medium caused the formation of a few clear zones. In order to investigate the contribution of $\mathrm{Na}_{2}$ EDTA to the antimicrobial activity of lysozyme against $E$. coli, the tests were also conducted with the films including $\mathrm{Na}_{2}$ EDTA alone as an antimicrobial agent. The careful analysis of Fig. 5a and b showed that when the porous surfaces of the films were in contact with target bacteria, using the combination of lysozyme with $\mathrm{Na}_{2}$ EDTA in films prepared with $5 \%$ and $15 \%$ CA solution resulted in $390 \%$ and $62 \%$ higher antimicrobial activity than using $\mathrm{Na}_{2}$ EDTA alone in the same films, respectively. At the dense surfaces of the films cast with $10 \%$ CA containing solutions, combined use of lysozyme and $\mathrm{Na}_{2}$ EDTA also showed $125 \%$ higher antimicrobial activity than using $\mathrm{Na}_{2}$ EDTA alone in the same type of films. In contrast, the total area of the fully formed zones formed at dense and porous surface of the films cast with $1.2 \% \mathrm{Na}_{2}$ EDTA in $5 \%$ or $10 \%$ CA solution were greater than those obtained with the dense and porous surfaces of similar films containing the combination of lysozyme and $\mathrm{Na}_{2}$ EDTA, respectively. The lower antimicrobial activity of lysozyme and $\mathrm{Na}_{2}$ EDTA combination than $\mathrm{Na}_{2}$ EDTA alone at the porous surfaces of films cast with $10 \%$ CA may be attributed to protein aggregates formed in these films by lysozyme which may block the pores, hence, decrease the diffusion of EDTA from the film into the agar medium. On the other hand, the high effectiveness of dense surfaces of $\mathrm{Na}_{2}$ EDTA containing films cast with $5 \% \mathrm{CA}$ is possibly due to heterogeneous distribution of $\mathrm{Na}_{2}$ EDTA between different sides of these films. The considerable difference between numbers and total areas of fully

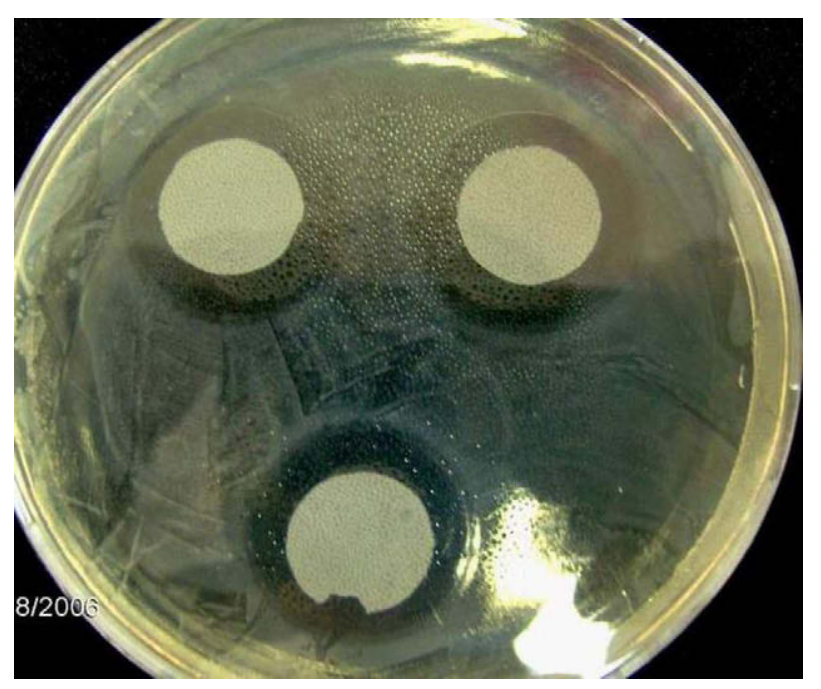

Fig. 4. Antimicrobial activity of porous surfaces of cellulose acetate films on $E$. coli. (CA/acetone/water/lysozyme/ $\mathrm{Na}_{2}$ EDTA weight percentages in film forming solutions were $5 / 80 / 12.3 / 1.5 / 1.2$ ). 
a

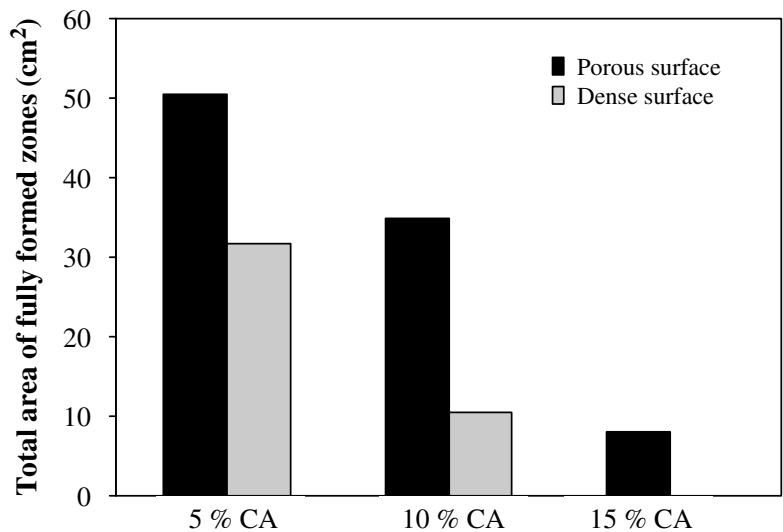

b

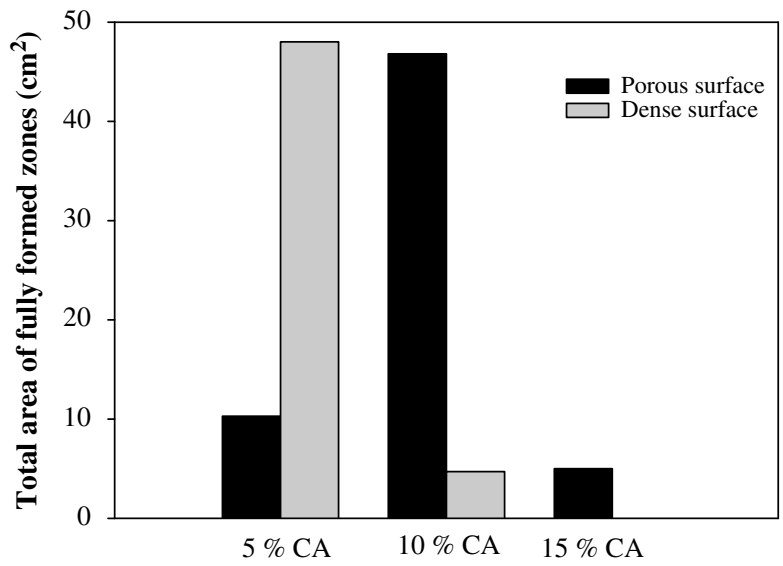

Fig. 5. The influences of cellulose acetate content and contact surface on antimicrobial activity of developed films on $E$. coli. (CA/acetone/water/lysozyme/ $\mathrm{Na}_{2}$ EDTA weight percentages in film forming solutions of (a) lysozyme and $\mathrm{Na}_{2}$ EDTA containing films were $(5,10$ or 15$) / 80 /(12.3,7.3$ or 2.3$) / 1.5 / 1.2$ and (b) $\mathrm{Na}_{2}$ EDTA containing films were $(5,10$ or 15$) / 80 /(13.8,8.8$ or 3.8$) / 0 / 1.2)$.

formed zones for dense and porous surfaces of $\mathrm{Na}_{2}$ EDTA containing films cast with $5 \%$ CA supports this hypothesis.

In tests conducted with $\mathrm{G}(+)$ bacteria, B. amyloliquefaciens, no zone formation was observed around the discs of films prepared with $1.5 \%$ lysozyme in different concentrations of CA solution. However, when film discs were removed carefully from the agar surface, a clear area was observed at all of the disc locations as shown in Fig. 6. In lysozyme-free control films, extensive growth was observed below the discs. This result showed the presence of antimicrobial activity of lysozyme against B. amyloliquefaciens. On the other hand, it is clear that this effect was limited to film contact surfaces at which the released lysozyme concentration was maximal.

\subsection{Stability of lysozyme in cold stored films}

For the standard release tests described in Section 3.2, the cast and dried films were used after they were cold stored overnight at $+4{ }^{\circ} \mathrm{C}$ in order to compare lysozyme activities released from different asymmetric films. To evaluate effects of long-term storage on lysozyme activity of CA films, the release tests were conducted for films stored at $+4{ }^{\circ} \mathrm{C}$ in dry form for a maximal period of 105 days. In these tests, the porous surfaces of the films prepared with $1.5 \%$ lysozyme in 5\% CA solution were used since these films released highest amount of enzyme activity. As seen in Fig. 7, the lysozyme released from the film cold stored for one day lost most of its activity between 23th and 30th h of release test. In contrast, in all films cold stored for more than 15 days the released activity did not drop considerably. Maximum lysozyme activities released from the films also increased continuously from $1167 \mathrm{U} / \mathrm{cm}^{2}$ to $1758 \mathrm{U} / \mathrm{cm}^{2}$ during cold storage of the films as shown in Table 4. Moreover, the immobilized lysozyme activity remained in the films increased $1.8-2.4$ fold for films cold stored $\geqslant 15$ days. The increased activity of soluble and immobilized lysozyme during cold storage suggests that the film production process caused some reversible changes in enzyme confirmation and resulted in temporary instability. It seems that the conformational changes in enzyme were caused by the solvent acetone used to dissolve CA. In fact, it is well known that the reduction of the dielectric constant of the medium in the presence of acetone favors electrostatic interactions which may cause some changes in conformation of enzyme (Harris, 1995). It is also reported that the interaction of acetone with proteins above $0{ }^{\circ} \mathrm{C}$ causes diffusion of acetone into interior parts of proteins and this may disrupt the hydrophobic interactions at these locations (Harris, 1995).

The increase of lysozyme activity by cold storage was also confirmed by test of antimicrobial activity of stored films on E. coli. For this purpose, the films prepared by $5 \%$ CA solution containing $1.5 \%$ lysozyme and $0.5 \%$ EDTA were tested on the target bacteria by the zone inhibition assay after 1 and 45 days of cold storage at $4{ }^{\circ} \mathrm{C}$. The EDTA concentration used in these antimicrobial tests was reduced from $1.2 \%$ to $0.5 \%$ to better evaluate the antimicrobial activity due to lysozyme. The results showed that the total area of the ffz has increased from 39 to $100.5 \mathrm{~cm}^{2}$ at the porous surfaces when the films were cold stored for 45 days. Similarly, 45 days of cold storage increased the total area of the $\mathrm{ffz}$ around dense surfaces a

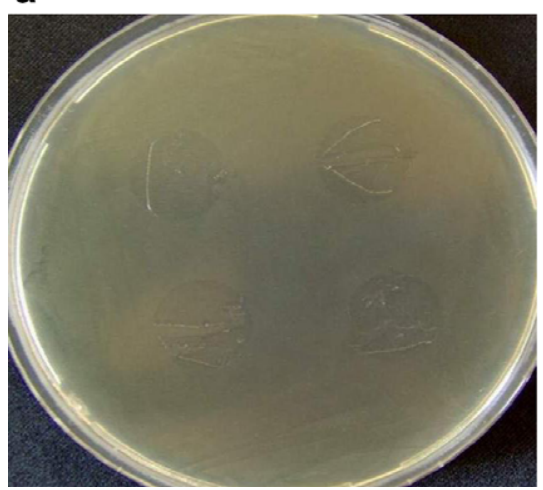

b

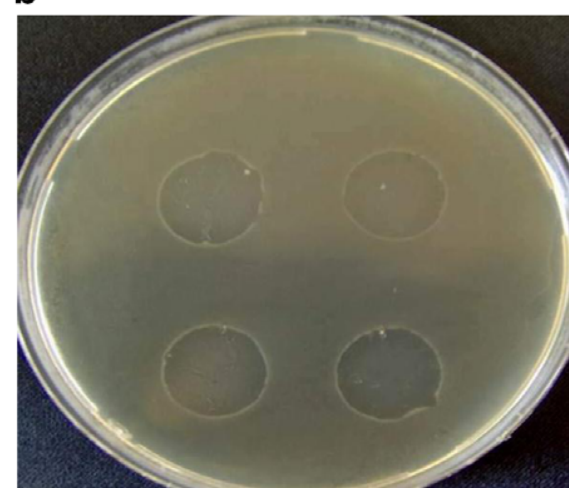

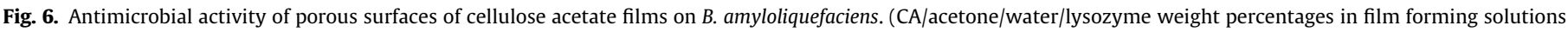
for (a) control and (b) lysozyme containing films were 5/80/15/0 and 5/80/13.5/1.5, respectively). 


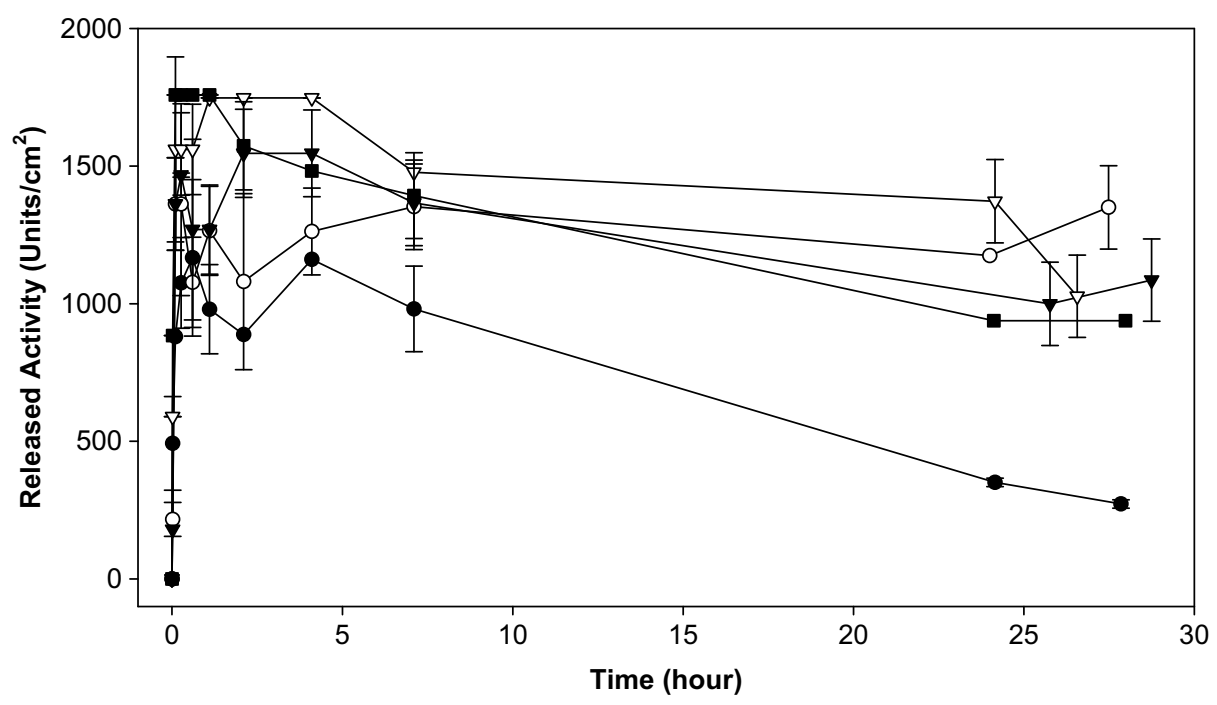

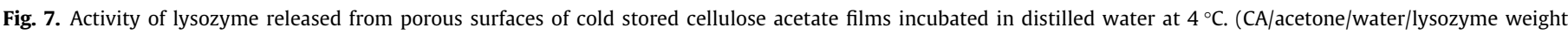
percentages in film forming solutions were 5/80/13.5/1.5; films were cold stored at $4{ }^{\circ} \mathrm{C}$ for $\bullet 1, \bigcirc 15, \nabla 21, \nabla 42, \boldsymbol{\square} 105$ days in dry form before release tests).

Table 4

Maximum released and immobilized activities of lysozyme from cold stored cellulose acetate films ${ }^{\mathrm{a}}$

\begin{tabular}{lll}
\hline $\begin{array}{l}\text { Storage time at } 4{ }^{\circ} \mathrm{C} \\
(\text { days) }\end{array}$ & $\begin{array}{l}\text { Maximum released activity } \\
\left(\text { Units } / \mathrm{cm}^{2}\right)\end{array}$ & $\begin{array}{l}\text { Immobilized activity } \\
\left(\text { Units } / \mathrm{cm}^{2}\right)\end{array}$ \\
\hline 1 & $1167 \pm 284$ & 63 \\
15 & $1362 \pm 168$ & 152 \\
21 & $1546 \pm 160$ & 145 \\
42 & $1748 \pm 0$ & 114 \\
105 & $1758 \pm 0$ & 130 \\
\hline
\end{tabular}

a CA/acetone/water/lysozyme weight percentages of these films were 5/80/13.5/ 1.5 .

b The films were cold stored in dry form before release tests were conducted by using their porous surfaces.

of the films from 23.2 to $104.3 \mathrm{~cm}^{2}$. These results confirmed our findings given in Table 4 that showed increased activity and stability of lysozyme in CA films by cold storage. The stability of lysozyme in the films during cold storage is particularly important since this is essential for commercializing pre-cast films.

\subsection{Effect of film composition on diffusion of lysozyme}

The rate limiting step of the release process for all films prepared is the diffusion of the active agent through the film. Hence, the key transport parameter that affects the release kinetics is the diffusivity of the active agent in the matrix. To determine the diffusion coefficients, the normalized release of lysozyme from CA films into water at $4{ }^{\circ} \mathrm{C}$ is plotted as shown in Fig. 8a-c. These curves represent the ratio of the amount of lysozyme released at time t, $M_{t}$, to the total amount released when equilibrium is reached, $M_{\infty}$. Table 5 lists the effective diffusion coefficient of lysozyme and its partition coefficients calculated from the normalized release curves using Eq. (8) and the equilibrium condition, respectively. As expected, diffusion coefficient of lysozyme in all films was higher when the porous side of the films was in contact with water. The largest difference in diffusivities through dense and porous side was obtained for the film prepared with $5 \%$ CA solution since large pores are present in that film. By increasing the CA/acetone ratio from $5 / 80$ to $15 / 80$ in the casting solution, the diffusivity of lysozyme decreased almost one order of magnitude while its partition coefficient increased. The partition coefficients determined using both sides of the films were almost same.
The results shown in Table 5 suggest that diffusion coefficient of lysozyme can be controlled by changing the composition of the film forming solution. Lower diffusivity of lysozyme in the film including higher CA content is caused by the increase in the fraction of dense layer and the decrease in the average pore size of the film. An excessively prolonged release of lysozyme from conventionally used dense films is expected due to large size of lysozyme, hence, its low diffusivity in the matrix. To increase the diffusion rate in these types of films, plasticizers and additives can be incorporated, however, they may adversely affect the initial protein conformation. Phase inversion technique used in this study allows to vary the fraction of dense skin layer, porosity, and pore size distribution without using any additives or plasticizers.

\subsection{Mechanical properties of the films}

Mechanical properties of the films were evaluated in terms of tensile strength, \% elongation at break and Young's modulus values which are related to structural characteristics of the films (Table 6). As expected, the tensile strength and elongation at break of the films increased with increasing CA concentration in the casting solution due to reduced pore sizes and porosity of the films. It can also be seen that Young's modulus increased with CA content. This is expected, as dense structures become stiffer and have higher modulus values than porous structures. Tensile strength and elongation at break values of the films prepared with $1.5 \%$ lysozyme in $5 \%$ and $10 \%$ CA solutions were found similar to those obtained with control films containing no lysozyme. In contrast, incorporation of lysozyme into the films prepared with 15\% CA solution caused a significant reduction in tensile strength and stretching ability (elongation at break) of the films prior to breakage. This can be attributed to incomplete dissolution of lysozyme in concentrated polymer solution with a reduced amount of water that results in non-homogeneous distribution of suspended lysozyme aggregates within the final film structure. In the presence of lysozyme, all films showed a slight increase in stiffness values.

\section{Conclusions}

In this study, lysozyme containing cellulose acetate based antimicrobial films were prepared using the dry phase inversion technique. The technique allowed us to develop novel food packaging 

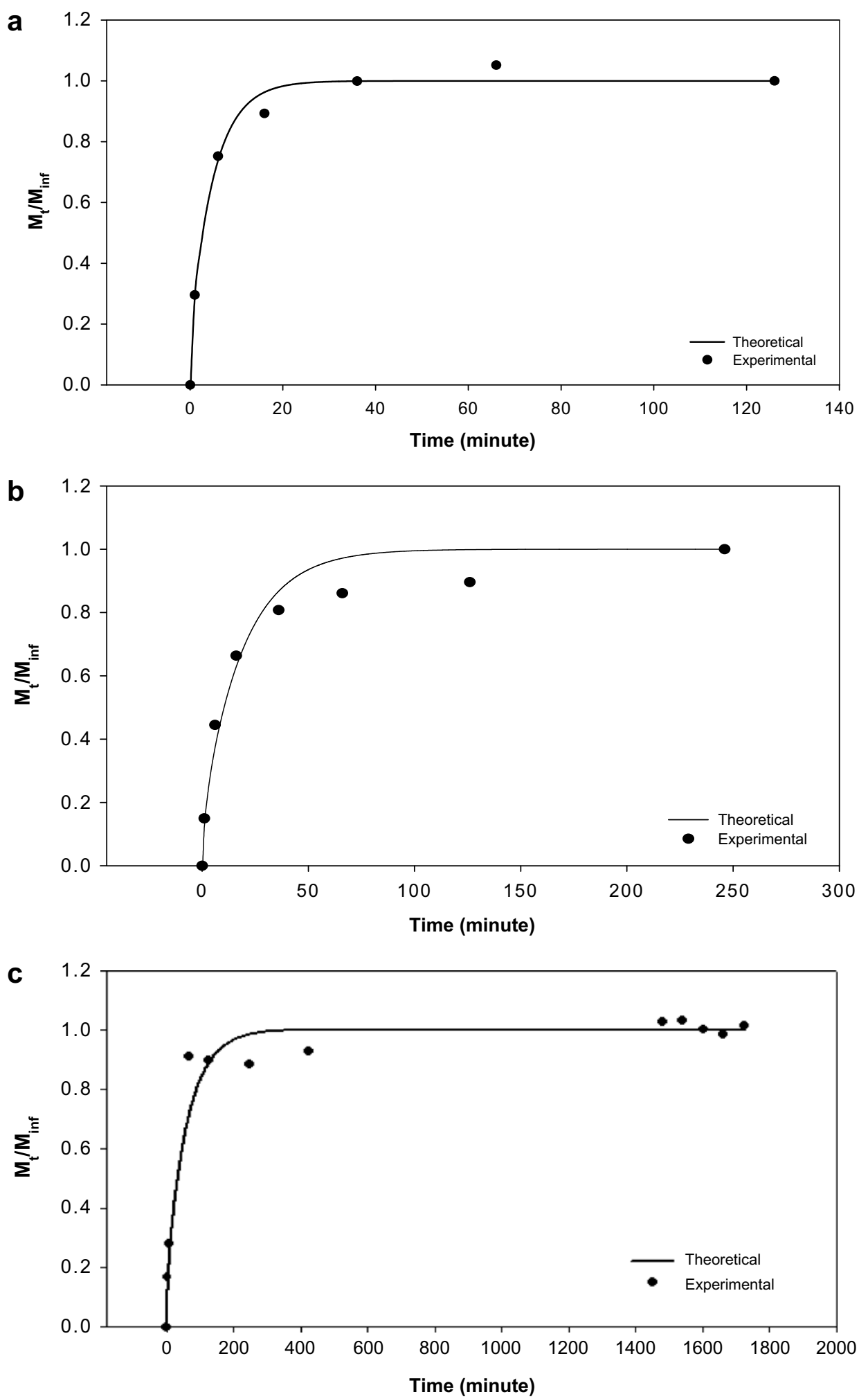

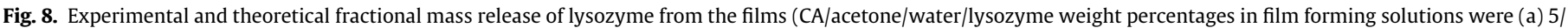
80/13.5/1.5-porous surface, (b) 5/80/13.5/1.5-dense surface, (c) 10/80/8.5/1.5-dense surface, respectively).

materials for the controlled release of the antimicrobial agent. The results showed that the release rates, maximum activity of lysozyme released and antimicrobial activities decreased while immobilized activities and tensile strength of the films increased with increasing CA content in the solution. The incorporation of lysozyme into the films prepared with $5 \%$ and $10 \%$ CA solution did not cause major changes in the mechanical properties of these films. On the other hand, significant reductions in tensile strength and elongation at break values of the antimicrobial films prepared with $15 \%$ CA solution were found compared to those of the lysozyme free films. The structure of the surface of the films influenced the lysozyme release rate. Finally, maximum activity of lysozyme 
Table 5

Effective diffusion and partition coefficients of lysozyme in different cellulose acetate films

\begin{tabular}{llll}
\hline Composition $^{\mathrm{a}}$ (wt\%) & Film surface & Partition coefficient & $D\left(\mathrm{~cm}^{2} / \mathrm{s}\right)$ \\
\hline $5 / 13.5$ & Porous & 234.34 & $2.33 \times 10^{-9}$ \\
& Dense & 269.26 & $6.17 \times 10^{-10}$ \\
$10 / 8.5$ & Porous & 318.73 & $2.33 \times 10^{-10}$ \\
& Dense & 296.29 & $1.83 \times 10^{-10}$ \\
$15 / 3.5$ & Porous & 814.56 & $4.17 \times 10^{-10}$ \\
& Dense & 825.80 & $1.50 \times 10^{-10}$
\end{tabular}

a Weight percentages of $\mathrm{CA} /$ water in film forming solutions. Weight percentages of acetone and lysozyme were $80 \%$ and $1.5 \%$ in all film forming solutions, respectively.

Table 6

Mechanical properties of lysozyme containing cellulose acetate films

\begin{tabular}{llll}
\hline $\begin{array}{l}\text { Composition } \\
\text { (wt\%) }\end{array}$ & $\begin{array}{l}\text { Tensile strength } \\
\text { (MPa) }\end{array}$ & $\begin{array}{l}\text { Elongation at break } \\
(\%)\end{array}$ & $\begin{array}{l}\text { Young's modulus } \\
(\mathrm{MPa})\end{array}$ \\
\hline $5 / 15 / 0$ & $10.37 \pm 1.61$ & $1.76 \pm 0.41$ & $257.52 \pm 46.84$ \\
$10 / 10 / 0$ & $37.05 \pm 1.70$ & $4.02 \pm 1.19$ & $1214.81 \pm 63.24$ \\
$15 / 5 / 0$ & $86.31 \pm 3.75$ & $12.00 \pm 1.58$ & $2068.33 \pm 94.73$ \\
$5 / 13.5 / 1.5$ & $10.35 \pm 2.48$ & $1.4 \pm 0.55$ & $387.22 \pm 50.34$ \\
$10 / 8.5 / 1.5$ & $40.49 \pm 3.40$ & $3.46 \pm 0.60$ & $1240.74 \pm 68.69$ \\
$15 / 3.5 / 1.5$ & $47.75 \pm 6.63$ & $4.27 \pm 1.79$ & $2057.09 \pm 714.43$ \\
\hline
\end{tabular}

${ }^{a}$ Weight percentages of CA/water/lysozyme in film forming solutions. Weight percentage of acetone was $80 \%$ in all film forming solutions.

released into the medium and antimicrobial activity of the films cast with 5\% CA solution increased with time during storage of the films in dry form at $4{ }^{\circ} \mathrm{C}$. It can be concluded that the main release mechanism is the diffusion of lysozyme through the films which is significantly influenced by the morphology of the films. The results clearly demonstrated that the structure of the films could be tailored by changing the composition of the initial casting solution. Based on the results, it is possible to suggest that asymmetric porous films containing antimicrobial agents can be used as novel internal food packaging materials with controlled release properties. However, further studies are needed to test the effectiveness of these films on selected food systems.

\section{Acknowledgment}

This work was funded by the research fund of İzmir Institute of Technology (Grant \# 2006 IYTE 26).

\section{References}

Altinkaya, S.A., Ozbas, B., 2004. Modeling of asymmetric membrane formation by dry-casting method. Journal of Membrane Science 230 (1-2), 71-89.

Altinkaya, S.A., Yenal, H., 2006. In Vitro Drug Release Rates from AsymmetricMembrane Tablet Coatings: Prediction of Phase-Inversion Dynamics. Biochemical Engineering Journal 28 (2), 131-139.

Amparo, L.R., Rafael, G., Lagaron, J.M., 2006. Bioactive packaging: turning foods into healthier foods through biomaterials. Trends in Food Science and Technology 17 (10), 567-575.

Appendini, P., Hotchkiss, J.H., 1997. Immobilization of lysozyme on food contact polymers as potential antimicrobial films. Packaging Technology and Science 10 (5), 271-279.

Appendini, P., Hotchkiss, J.H., 2002. Review of antimicrobial food packaging. Innovative Food Science and Emerging Technologies 3 (2), 113-126.

Arifin, D.Y., Lee, L.Y., Wang, C.H., 2006. Mathematical modeling and simulation of drug release from microspheres: Implications to drug delivery systems. Advanced Drug Delivery Reviews 58 (12-13), 1274-1325.

Brayden, D.J., 2003. Controlled release technologies for drug delivery. Drug Discovery Today 8 (21), 976-978.

Buonocore, G.G., Conte, A., Corbo, M.R., Sinigaglia, M., Nobile, M.A., 2005. Mono- and multilayer active films containing lysozyme as antimicrobial agent. Innovative Food Science and Emerging Technologies 6 (4), 459-464.

Buonocore, G.G., Del Nobile, M.A., Panizza, A., Bove, S., Nicolais, L., 2003. Modeling the lysozyme release kinetics from antimicrobial films intended for food packaging applications. Food Engineering and Physical Properties 68 (4), 13651370.

Buonocore, G.G., Sinigaglia, M., Corbo, M.R., Bevilacqua, A., La Notte, E., Del Nobile, M.A., 2004. Controlled release of antimicrobial compounds from highly swellable polymers. Journal of Food Products 67 (6), 1190-1194.

Cardinal, J.R., Herbig, S.M., Korsmeyer, R.W., Lo, J., Smith, K.L., \& Avinash, G. (1997). Use of asymmetric-membranes in delivery devices. U.S. Patent No. 5 612, 059.

Conte, A., Buonocore, G.G., Sinigaglia, M., Del Nobile, M.A., 2007. Development of immobilized lysozyme based active film. Journal of Food Engineering 78 (3), $741-745$.

Crank, J., 1975. The mathematics of diffusion, second ed. Oxford University Press, Oxford.

De Roever, C., 1998. Microbiological safety evaluations and recommendations on fresh produce. Food Control 9 (6), 321-347.

Devlieghere, F., Vermeiren, L., Debevere, J., 2004. New preservation technologies: possibilities and limitations. International Dairy Journal 14 (4), 273-285.

Güçbilmez, Ç.M., Yemenicioğlu, A., Arslanoğlu, A., 2007. Antimicrobial and antioxidant activity of edible zein films incorporated with lysozyme, albumin proteins and disodium EDTA. Food Research International 40 (1), 80-91.

Han, J.H., 2000. Antimicrobial food packaging. Food Technology 54 (3), 56-65.

Han, J.H., Floros, J.D., 1998. Simulating diffusion model and determining diffusivity of potassium sorbate through plastic to develop antimicrobial packaging films. Journal of Food Processing and Preservation 22 (2), 107-122.

Harris, D.A., 1987. Spectrophotometric assays. In: Harris, D.A., Bashford, C.L. (Eds.), Spectrophotometry and spectrofluorometry. I.R.L. Press, Oxford (pp. 59-60).

Harris, E.L.V., 1995. Concentration of Extracts. In: Harris, E.L.V., Angal, S. (Eds.), Protein purification techniques. Oxford University Press, Oxford (pp. 157160).

Herbig, S.M., Cardinal, J.R., Korsmeyer, R.W., Smith, K.L., 1995. Asymmetric membrane tablet coatings for osmotic drug delivery. Journal of Controlled Release 35 (2-3), 127-136.

Jiang, C.M., Wang, M.C., Chang, W.H., Chang, H.M., 2001. Isolation of lysozyme from hen egg albumen by alcohol-insoluble cross-linked pea pod solid ion-exchange chromatography. Journal of Food Science 66 (8), 1089-1092.

Labuza, T.P., Breene, W.M., 1989. Applications of "active packaging" for improvement of shelf-life and nutritional quality of fresh and extended shelflife foods. Journal of Food Processing and Preservation 13 (1), 169.

LaCoste, A., Schaich, M., Zumbrunnen, D., Yam, K.L., 2005. Advancing controlled release packaging through smart blending. Packaging Technology and Science 18 (2), 77-87.

Langer, R.S., Peppas, N.A., 1981. Present and future applications of biomaterials in controlled drug delivery systems. Biomaterials 2 (4), 201-214.

Leong, K.W., Langer, R., 1988. Polymeric controlled drug delivery. Advanced Drug Delivery Reviews 1 (3), 199-233.

Lin, Y.K., Ho, H.O., 2003. Investigations on the drug releasing mechanism from an asymmetric-membrane-coated capsule with an in situ formed delivery orifice. Journal of Controlled Release 89 (1), 57-69.

Mallapragada, S.K., Peppas, N.A., 1997. Crystal dissolution-controlled release systems: I. Physical characteristics and modeling analysis. Journal of Controlled Release 45 (1), 87-94.

Mecitoğlu, Ç., Yemenicioğlu, A., Arslanoğlu, A., Elmacı, Z.S., Korel, F., Çetin, A.E. 2006. Incorporation of partially purified hen egg white lysozyme into zein films for antimicrobial food packaging. Food Research International 39, 12-21.

Prabakaran, D., Singh, P., Jaganathan, K.S., Vyas, S.P., 2004. Osmotically regulated asymmetric capsular systems for simultaneous sustained delivery of antitubercular drugs. Journal of Controlled Release 95 (2), 239-248.

Quintavalla, S., Vicini, L., 2002. Antimicrobial food packaging in meat industry. Meat Science 61 (4), 373-380.

Richard, C., 1998. Mathematical modeling of controlled release from implanted drug impregnated monoliths. Pharmaceutical Science and Technology Today 1 (6), 269-276

Siepmann, J., Peppas, N.A., 2001. Modeling of drug release from delivery systems based on hydroxypropyl methylcellulose (HPMC). Advanced Drug Delivery Reviews 48 (2-3), 139-157.

Siepmann, J., Lecomte, F., Bodmeier, R., 1999. Diffusion-controlled drug delivery systems: calcu-lation of the required composition to achieve desired release profiles. Journal of Controlled Release 60 (2-3), 379-389.

Smith, K.L., Herbig, S.M., 1992. Controlled Release. In: Winston, W.S., Sirkar, K.K (Eds.), Membrane handbook. Van Nostran Reinhold, New York.

Suppakul, P., Miltz, J., Sonneveld, K., Bigger, S.W., 2003. Active packaging technologies with an emphasis on antimicrobial packaging and its applications. Journal of Food Science 68 (2), 408-420.

Thombre, A.G., Cardinal, J.R., DeNoto, A.R., Gibbes, D.C., 1999a. Asymmetric membrane capsules for osmotic drug delivery. Part II: in vitro and in vivo drug release performance. Journal of Controlled Release 57 (1), 65-73.

Thombre, A.G., Cardinal, J.R., DeNoto, A.R., Herbig, S.M., Smith, K.L., 1999b. Asymmetric-membrane capsules for osmotic drug delivery. Part I: development of a manufacturing process. Journal of Controlled Release 57 (1) 55-64.

Thombre, A.G., DeNoto, A.R., Gibbes, D.C., 1999c. Delivery of glipizide from asymmetric-membrane capsules using encapsulated excipients. Journal of Controlled Release 60 (23), 333-341.

Wang, D.M., Lin, F.C., Chen, L.Y., Lai, J.Y., 1998. Application of asymmetric TPX membranes to transdermal delivery of nitroglycerin. Journal of Controlled Release 50 (13), 187-195. 